\title{
ANALYSIS OF THE EFFECTS OF TECHNOLOGY AND DIGITALIZATION ON BANKING IN TERMS OF AUDIT AND SURVEILLANCE
}

\section{DOI: 10.17261/Pressacademia.2021.1490}

PAP- V.14-2021(16)-p.75-79

Cihan Sari

Istanbul Commerce University, Finance Institute, Banking Department, Istanbul, Turkey. cihan.sari@istanbulticaret.edu.tr, ORCID: 0000-0003-2735-8881

\author{
To cite this document \\ Sari, C., (2021). Analysis of the effects of technology and digitalization on banking in terms of audit and surveillance. PressAcademia Procedia \\ (PAP), 14, 75-79. \\ Permanent link to this document: http://doi.org/10.17261/Pressacademia.2021.1490 \\ Copyright: Published by PressAcademia and limited licensed re-use rights only
}

\section{ABSTRACT}

Purpose- The aim of the study is to focus on the direction of developments in products and services by analyzing technological developments and digitalization in terms of both customers and banks.

Methodology- This study explains the situation of banking against technology with "Economic Wave Theory". It reveals the digitalization need of banks and the expectations of customers from banks with approaches in the literature.

Findings- It is known that technological developments have effects on human life as well as on all sectors. Banking, on the other hand, has a position ahead of other sectors in applying technological developments and incorporating them into their systems. It reveals that banking is in a closer relationship with technology day by day and digital transactions should be protected in terms of confidentiality, security and integrity. Today, there is a greater need for information systems to establish a closer relationship with internal control, audit and risk management and to prevent financial crimes. For this reason, it has been observed that "Regulatory Technology" and "Supervisory Technology" ecosystems should be placed next to the "Financial Technology" ecosystem.

Conclusion- As a result, it has been concluded that Financial Technologies and digitalization alone will not be sufficient, and that digitalization should be used in the regulations, audit and surveillance.

Keywords: Digitization, artificial intelligence, fintech, regtech, suptech JEL Codes: G20, G30, O30

\section{TEKNOLOJi VE DiJiTALLEŞMENIN BANKACILIĞA ETKILERININ DENETIM VE GÖZETIM AÇISINDAN ANALIZi}

\section{ÖZET}

Amaç- Çalışmanın amacı, teknolojik gelişmeleri ve dijitalleşmeyi hem müşteriler hem de bankalar açısından analiz ederek ürün ve hizmetlerdeki gelişmelerin yönüne odaklanmaktır.

Metodoloji- Bu çalışma Bankacılığın teknoloji karşısındaki durumunu "Ekonomik Dalga Teorisi" ile açıklamaktadır. Bankaların dijitalleşme ihtiyacını ve müşterilerin bankalardan beklentilerini literatürdeki yaklaşımlar ile ortaya koymaktadır.

Bulgular- Teknolojik gelişmelerin insan yaşamına etkileri olduğu kadar insana dokunan tüm sektörlere de etkileri olduğu bilinmektedir. Bankacılık ise günümüzde teknolojik gelişmeleri uygulamak ve sistemlerine dahil etmek konusunda diğer sektörlerin önünde bir konuma sahiptir. Bankacılığın gün geçtikçe teknoloji ile daha yakın ilişki içerisine girdiğini ve dijital işlemlerin gizlilik, güvenlik ve bütünlük açısından korunması gerektiğini ortaya koymaktadır. Günümüzde bilgi sistemlerinin iç kontrol, denetim ve risk yönetimi ile daha yakın ilişki kurmasına ve mali suçların engellenmesine daha fazla ihtiyaç bulunmaktadır. Bu nedenle FinTech (Financial Technology) ekosisteminin yanına RegTech (Regulatory Technology) ve SupTech (Supervisory Technology) ekosistemlerinin de konulmasına gerektiği gözlenmiştir.

Sonuçlar- Sonuç olarak ise, finansal teknolojilerin ve dijitalleşmenin tek başına yeterli olmayacağı, yasal düzenlemeler, denetim ve gözetim alanlarında da dijitalleşmenin kullanılması gerektiğini sonucuna ulaşılmıştır.

Anahtar Kelimeler: Dijitalleşme, yapay zeka, fintech, regtech, suptech JEL Kodları: G20, G30, O30 


\section{GiRiş}

Bireylerin yaşamlarına etki eden faktörlerden en önemlisi, teknoloji1'dir. Teknoloji, genel olarak günlük yaşantımızda gerçekleştirdiğimiz işlerin süresini kısaltan ve/veya kalitesini artıran ya da hayatımızda daha önce olmayan bir ürün ve hizmeti yaşantımıza dâhil eden yenilikler olarak tanımlanmaktadır.

Tarihsel olarak izlendiğinde ise teknolojinin yaşam biçimlerini etkilemesi, iş süreçlerini değiştirmesi ve olmayan ürünler ile hizmetleri yaşama katması durağan şekilde gerçekleşmediği; aksine uzun yıllara yayıldığı gözlenmektedir. 1700'lü yılların sonunda itibaren hızlanan gelişmelerin Sanayi Devrimi ile başladığı kabul edilmekte ve ardından gelen yıllar beş farklı yükseliş ve çöküşü içeren dalga teorisi ile açıklanmaktadır. Rus iktisatçı Nikolai Dimitrievic Kondratieff tarafından geliştirilen teoriye göre "40-50 yıllık dönemlerde bir teknolojik gelişmenin tetiklediği yenilikler yaşamın ve ekonominin seyrini belirlemektedir." (Öztürk \& Akdağ, 2017)

Dalga Teorisine göre ise; her dalga diliminde Gelişme, Refah, Durgunluk ve Depresyon aşamaları yer almakta; söz konusu dört aşama geçildiğinde sonraki dalga başlamaktadır. Aynı zamanda teorinin en önemli unsuru her dalgayı bir teknolojik gelişmenin tetiklemesidir. İlk dalganın tetikleyicisi, pamuk ve demirin yaygın kullanımını sağlayan makineler olurken ikinci dalga, buharlı makineler ve demiryollarındaki gelişmelerle başlamaktadır. Üçüncü dalga elektrik kullanımının yaygınlaşması, dördüncü dalga petrol ve motorlu araçların her alana girmesi ile başlamaktadır. Beşinci Dalga Mikroelektronikler (Chip’ler) sayesinde bilgi ve iletişim teknolojilerinin dönemi olmuştur. Bilgisayarlar ile üretim yapııması, iletişim ağları ve dijital bankacılık tüm dalga içerisinde yayılmıştır. İçinde bulunduğumuz altıncı dalganın tetikleyicisi ise Yapay Zekâ'lı (Artificial Intelligence - Al) sistemlerdir.

\section{Şekil 1: Kondratieff Dalgaları}

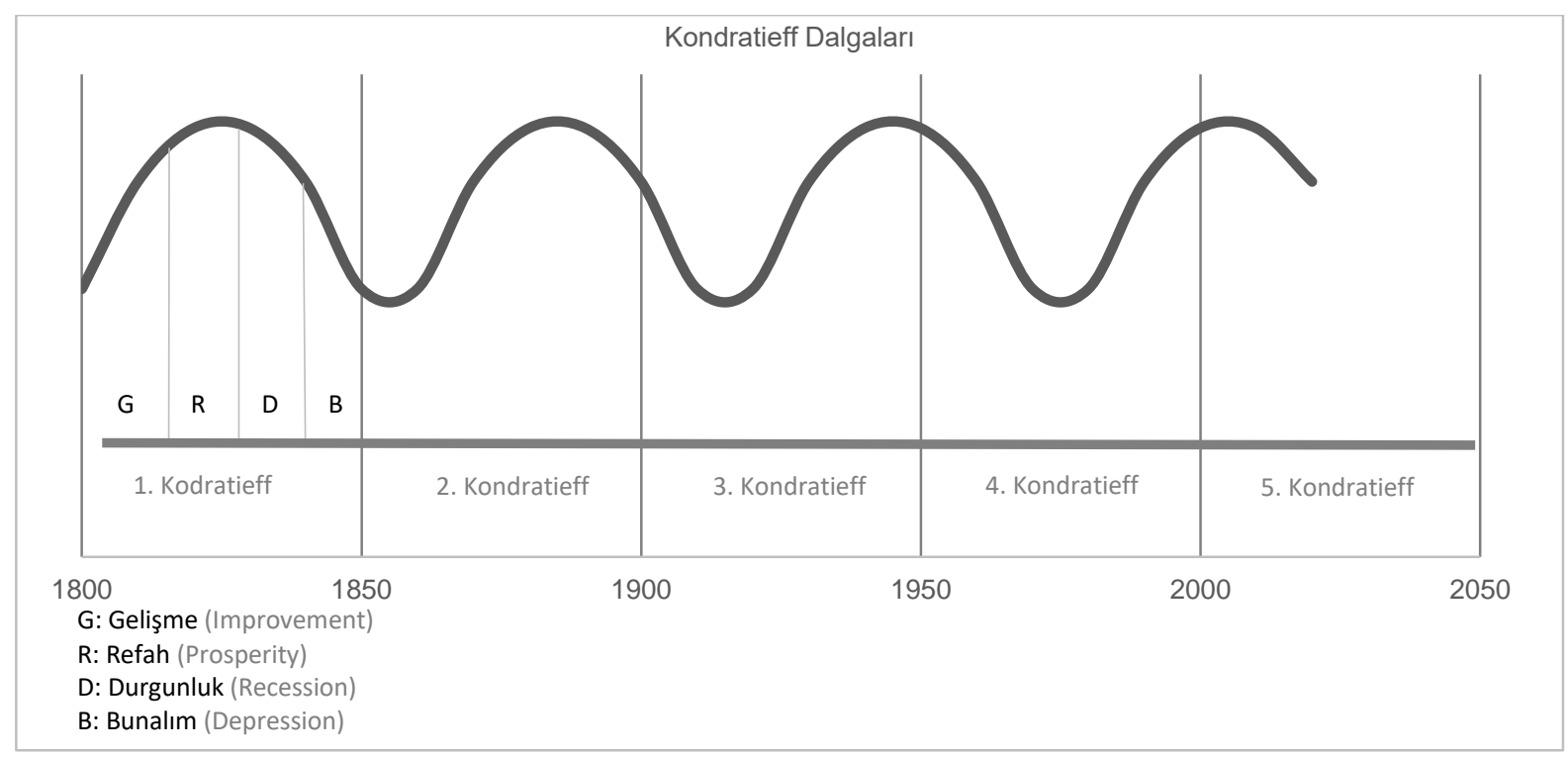

Dalgaların değişiminde ise ekonomik krizler bulunmaktadır. Bankacılık ise krizlerden etkilenen sektörlerden olması nedeni ile sonraki yeniliklere hızla adapte olmaktadır.

\section{TEKNOLOJI VE BANKACILIK ILIŞKISI}

\subsection{Dalga Teorisi'nde Bankacilık}

Teknolojik yenilikler, bireylerin yaşamlarını olduğu kadar bankacılık ekosistemini de değiştirmiştir. Yeniliklerin çeşitli ekonomik sektörlerde yeni hizmetlere, yeni iş tanımlarına ve yeni yönetim işlevlerine nasıl yol açtı̆ııı anlamak için 'teknolojik devrim' ve 'yeni ekonomi' gibi yeni terimler dahi icat edilmiştir. Tarihsel süreç içerisinde bankacılık 4. Dalga'da ATM (Automated Teller Machine - Otomatik Vezne Makinesi) gibi cihazlar ile otomasyon süreçlerine girmiş, 5 . Dalga'da teknoloji ile iç içe olmuş ve içinde bulunduğumuz 6 . Dalga'da ise teknolojinin en önemli sektörü haline gelmiştir.

\footnotetext{
${ }^{1}$ Teknoloji: Belli amaçlara ulaşmada, belli sorunları çözmede, gözleme dayalı ve kanıtlanmış bilgilerin uygulanmasıdır. (Demirel, 1993)
} 
Tablo 1: Ekonomik Dalgalardaki Teknolojik Gelişme Periyotları

\begin{tabular}{|c|c|c|c|c|}
\hline Dalgalar & Tarih & Anahtar Yenilikler & Endüstriyel Organizasyon & Öncü Sektörler \\
\hline 1. Dalga & 1770 & Pamuklu bez - dökme demir & Erken Makineleşme & $\begin{array}{l}\text { - Tekstil } \\
\text { - Su gücü }\end{array}$ \\
\hline 2. Dalga & 1840 & Buhar, Demiryolları, Çelik & Buhar gücü ve demiryolları & $\begin{array}{l}\text { - Buhar makineleri } \\
\text { - Makine araçları } \\
\text { - Demiryolları }\end{array}$ \\
\hline 3. Dalga & 1890 & Elektrik ve Mühendislik & Elektrik Mühendisliği & $\begin{array}{l}\text { - Mühendislik } \\
\text { - Sentetikler } \\
\text { - Elektrik bilimi }\end{array}$ \\
\hline 4. Dalga & 1940 & Petrol, Enerji & Fordist Kitlesel Üretim & $\begin{array}{l}\text { - Otomobiller } \\
\text { - Uçaklar } \\
\text { - Dayanıklı tüketim malları }\end{array}$ \\
\hline 5. Dalga & 1990 & Mikroelektronikler & $\begin{array}{l}\text { Bilgi ve İletişim } \\
\text { Teknolojileri }\end{array}$ & $\begin{array}{l}\text { - Bilgisayarlar } \\
\text { - Iletişim ağları } \\
\text { - Dijital bankacılık }\end{array}$ \\
\hline 6. Dalga & $\begin{array}{l}2015- \\
2035\end{array}$ & Yapay Zekâ & Biyoteknoloji & $\begin{array}{l}\text { - Yapay Zekâ } \\
\text { - Nano Teknoloji } \\
\text { - Akıllı Fabrikalar }\end{array}$ \\
\hline
\end{tabular}

Altıncı dalgadaki bankacılık yenilikleri, yapay zekâ gibi çı̆̆ır açan teknolojilerin ve ayrıca dijital kanalların yayılması ve artan erişilebilme ihtiyacının bir sonucu olarak ortaya çıkmıştır.

(IMF, 2017) "Teknolojideki hızlı ilerlemelerin finansal hizmetler ortamını dönüştürdüğünü” ifade ederek ve sektörün küresel olarak yeniden şekillenmesinden de anlaşılacağı gibi, bankalar ve diğer finans kuruluşlarının bu değişimin bir parçası olduğunu vurgulamaktadır.

(Carbó-Valverde, Cuadros-Solas, \& Rodríguez-Fernández, 2020) çalışmalarında Bankacılık sektörünün, Bilgi Teknolojileri (BT) Yatırımlarında tüm sektörlerin üzerinde yatırımla bu alanda ilk sırada olduğunu ifade etmektedir. Yine aynı çalışmada, finansal hizmetler sektörünün diğer tüm sektörlerde kullanıcı başına en büyük BT yatırımına sahip olduğu belirtilmiştir.

(Casolaro \& Gobbi, 2007) çalışmalarında, henüz teknolojinin bankacılık üzerinde bu günkü kadar kapsayıcı etkisinin görülmediğini, 1989 2000 yılları arasında 600 İtalyan bankası üzerinde yaptıkları araştırmada teknoloji yatırımı yapan bankaların kârlıık düzeylerinin sadece teknoloji yatırımından kaynaklı olarak yılda \%1,3 ila \%1,8 arasında arttığını belirlemişlerdir.

(Asadi, Nilashi, Husin, \& Yadegaridehkordi, 2017) çalışmalarında ise Bankaların BT yatırımları çoğunlukla müşterilerin deneyimlerini doğrudan iyileştirebilecek dijital teknolojilere yöneldiğini ve müşterilerine yenilikleri tahsis ettiklerini belirtmektedir.

Süreç içerisinde banka müşterilerinin tercihleri de önemli ölçüde değişmektedir. Teknolojik yenilikler ortaya çıktıkça, müşteriler de bankalar gibi yeni teknolojileri benimsemektelerdir. Bankaların sunduğu dijital hizmetler güvenli, kullanışlı ve erişilebilir olduğunda müşteriler tarafından kabul gördüğü ancak bu hizmetler pahalı ve karmaşık olarak algılandığında müşteriler bu hizmetleri kullanmamaya karar verebildiği (Xue, Hitt, \& Chen, 2011) çalışmasında tespit edilmiştir.

\subsection{Bankacılıkta Teknoloji Kullanımının Tarihsel Gelişimi}

Bankacılığın teknoloji ile tanışmasına neden olamasa da müşterilerin dijital kanallara yönlendirilmesinin / şubelerden uzaklaştırılmasının hassas noktası, ATM'lerin geliştirilmesi ve yaygınlaştırılmasıdır. Özellikle şubelerin tatiller de dahil olmak üzere tüm gün açık tutulması mümkün olmadığından ATM'ler şubelerden daha ucuz ve etkili bir çözüm yolu olmuştur. (Bátiz-Lazo, 2018) 'ya göre ATM'ler yüksek teknolojileri barındırdığı için, bilgisayar teknolojisi ve bankacılık uygulamaları arasındaki etkileşimi araştırmak için başlangıç noktası olmalıdır. Ayrıca bankacılıkta iç ve dış değişime açılan pencere olarak tanımladığı bu cihazları; klasik şube bankacılığından dijitalleşmeye evirilme noktası olarak görmektedir.

Plastik kartların kullanımının yaygınlaşması ve gelişmesi POS (Point of Sale - Satış Noktası) cihazlarının yaygınlaşmasına, ödeme sistemlerinin artmasına neden olmuştur. Bu gelişmeler beraberinde para transfer sistemlerinin çeşitlenmesi ve İnternet Bankacılığının yaygınlaşarak gelişmesine de yol açmıştır. Bu gelişmelerle birlikte müşteri ihtiyaçlarının karşılanabilmesi için entegre ve küresel sistemler tasarlanmış ve işletile geçmiştir.

Günümüzde ise dijitalleşen bankalar, mobil uygulamalar, akıllı televizyonlar, sosyal medya ve üçüncü parti uygulamalar üzerinden açık bankacılık vb. şekillerde hizmetlerini sürdürmektedirler. Özellikle 2020 yılı başlarında itibaren tüm dünya ülkelerini etkisi altına alan Pandemi nedeni ile dijitalleşme en yüksek seviyesine ulaşmıştır. Bankalar ise nakde olan ihtiyacın azaldığı bu süreçte sundukları dijital ürün ve hizmetler ile önemli rol almışlardır. 
(Crowley, 2019) çalışmasında "Ekonominin nakitsiz olup olmayacağının tartışıldığı günümüzde ATM'nin toplumdaki rolünün önümüzdeki yarım yüzyılda önceki yarım yüzyılda olduğu kadar merkezi olup olmayacağını sadece zaman gösterecek." demek sureti ile dünyanın bir bölümünün hızlı biçimde mobil ödemeler gibi teknolojilere adapte olurken bir bölümünde gelişmelerin yavaş ilerlediğine vurgu yapmaktadır.

\section{BANKACILIK TEORISI AÇISINDAN TEKNOLOJiK DÖNÜŞÜM VE DiJiTALLEŞME}

\subsection{Müşterilerin Dönüşümü ve Dijitalleşme îhtiyacı}

(Organisation for Economic Co-operation and Development (OECD), 2017) dijitalleşmeyi, dijital veya bilgisayar teknolojisinin bir tüketici tarafından benimsenmesi veya kullanımının artması olarak tanımlamaktadır. Tüketicilerin yani banka müşterilerinin ise son yıllarda değişen alışkanları neticesinde; 2018'de OECD ülkelerindeki internet kullanıcılarının \%60'ından fazlasının internet veya mobil bankacılığı kullandığı gözlemlenmiştir. Yine aynı müşterilerin \%76'sının banka hesaplarını kullanarak en az bir dijital ödeme yaptığı tespit edilmiştir.

Literatürde ise online bankacılık kanalları yoluyla müşterilerin dijitalleşmesinin, farklı teknolojileri benimseme teorileri çerçevesinde incelendiği gözlenmektedir.

(Davis, Bagozzi, \& Warshaw, 1989) çalışması ile müşterilerin yeni bir teknolojiyi benimseme kararının algılanan kullanışlılı̆a ve kullanım kolaylığına dayandığını öne sürmüştür. Algılanan kullanım kolaylığının belirleyicileri olarak bireysel farklılıkların, sistem özelliklerinin, sosyal etkinin ve kolaylaştırıcı koşulları içeren dönüşümlerin müşterilerce kabul gördüğü sonucuna ulaşılmıştır. Teoriye göre, yeniliklerin yaygınlaşması görev-teknoloji uyumu ile sunulan ürün ve hizmetlerde başarıya ulaşmaktadır.

Deneysel olarak bazı çalışmalar, müşterilerin güvenlik algılarının, kullanım zorluğunun ve algılanan maliyetlerin dijital bankacılığın benimsenmesinde yavaşlatıcı güç olduğunu göstermiş olsa da hizmet kolaylığı ve algılanan kalite, dijitalleşmenin ortak belirleyicileri olarak ortaya çıkmıştır. (Carbó-Valverde, Cuadros-Solas, \& Rodríguez-Fernández, 2020) çalışmalarına göre dijital bankacılık hizmetlerinin benimsenmesinin bilgiye dayalı hizmetlerle (Örn.: Hesap bakiyesinin kontrol edilmesi) başladığı, bunda sorun yaşanmazsa güven oluştuğu ve ardından finansal işlem (Örn.: Para transferi) yapıldığını göstermiştir

Bu neticeler ile bankaların müşterilerin gerek mevduatlarını bankalara vermeleri gerek ise kredi kullanma işlemleri için bankalardan dönüşüm ve dijitalleşme bekledikleri sonucuna ulaşılabilmektedir.

\subsection{Bankaların Dönüşümü ve Dijitalleşme Yaklaşımı}

Bazı çalışmalar bankaların dijital ürün ve hizmetleri müşteri açısından değil bankanın performansı ve verimliliği gereği olarak sunduğunu ifade etse de bir kısım çalışmalar ise bankaların rakipleri tarafından tetiklendiğini kanıtlamaktadır.

(He, 2015) çalışmasında, mobil bankacılık alanında bankaların rakiplerini izlediğine dair kanıtlar sunmuştur. Ayrıca dijital ürün ve hizmetler sunan bankalar için dijital kanallardan işlem yapan müşterileri elde tutmak kolaylaşmakta ve müşteriler daha fazla işlem yaptığı için sunulan ürünlerden daha fazla kâr elde edilebilmektedir. Bu da bankaları yeni dijital ürünler sunma konusunda isteklendirmektedir.

(Mishkin, 2007) çalışmasında "Finansal çevredeki bir değişiklik, finansal kurumları, daha kârlı olma ihtimali olan yenilikleri araştırmaya yöneltir." demek suretiyle bankaların teknolojik gelişmelerden beklentilerini ortaya koymuştur.

Bankalar teorik birçok uluslararası ve yerel kanunlara, yönetmelik ve kurallara, düzenleyici ve denetleyici otoritelerin gözetimine, özetle regülasyonlara uymak zorundadır. Bu zorunluluklar ise bankaların her teknolojik gelişmeyi uygularken kurallara uygun ürün ve hizmetler sunmalarını beraberinde getirmektedir.

Uygulamaya geçen ve son yıllarda gittikçe yaygınlaşan ve daha da yaygınlaşması beklenen finansal teknolojiler (FinTech) büyük verilerden oluşmakta büyük verilerin kurallara uygunluğu da yine finansal teknolojiler (yani bilgisayar sistemleri ile) yardımı ile yapılmaktadır. Kontrol ve denetleme yapılarının da FinTech gelişmeleri ile doğru orantılı olarak gelişmesi hatta daha öncesinde geliştirilmesinin kaçınılmaz olduğu değerlendirilmektedir.

\section{SONUÇ VE DEĞERLENDIRME}

Dijitalleşmenin bankalar açısından müşteri ihtiyaçlarına hızlıca cevap vermek, kârlılık, verimliliği arttırmak, rekabet avantajı, pazara girme hızının artması, müşteri bağılığını arttırmak veya yeni müşterileri kazanmak vb. nedenler ile benimsendiği gözlenmektedir. Bu cesaretlendirici etkileri bankalar iyi biçimde değerlendirmektedirler.

Bunların dışında (her biri ayrı birer çalışmanın konusu olacak kapsamdaki) hukuki düzenlemelere, finansal tüketicinin korunmasına, müşteri tanımaya, mesafeli sözleşmeler yapılmasına, ürün ve hizmetlere erişebilme ücretlerin yeterli ucuzlukta olmasına, bilgi sistemlerine yönelik düzenlemelerin iç kontrol, denetim ve risk yönetimi ile daha yakın ilişki kurmasına, mali suçların engellenmesine daha fazla ihtiyaç bulunduğu gözlenmektedir.

Henüz FinTech ekosisteminin finansal sistemi tek başına yönlendirebilecek büyüklüğe ulaşmadığından mevcuttaki düzenlemeler çoğunlukla FinTech geliştiricilerini teşvik edici ve mevcut finansal sistemi tehlikeye atmadan teknolojik uygulamaların adaptasyonunu sağlayıcı yapıya sahiptir denebilmektedir. Yeni düzenlemelerde ise çokça RegTech olarak bilinen Düzenleyici Teknolojilere ve SupTech olarak bilinen Gözetim Teknolojisine ağırlık verildiği gözlenmektedir. 
(Buttar, 2019) çalışmasında "RegTech ve SupTech alanlarındaki bu gelişmelerin bir sonucu olarak yakın bir gelecekte düzenleyici çerçevenin giderek bankalardan veri toplamaya dayalı bir yapıdan, gerekli verilerin anında elde edilerek gerekli değerlendirme ve analizlerin daha kapsamlı bir şekilde gerçekleştirilmesinin mümkün olacağı bir yapıya evrilmesi beklenmektedir." demek suretiyle gelişmelere vurgu yapmaktadır.

(Feridun, 2020) çalışmasında "Nitekim, son birkaç yılda birçok ülkede düzenleyici otoritelerin bu yönde birtakım çalışmalar gerçekleştirmeye başlamış olduğu görülmektedir. Bu konudaki gelişmelerin son yıllarda özellikle Birleşik Krallık'ta hız kazanmakta olduğu bilinmektedir. Önümüzdeki on yılda düzenleyici verilerin otomatik olarak toplanması, muhafaza edilmesi ve değerlendirilmesine ilişkin olarak bir geliştirme süreci başlatarak, bu alanda Al teknolojilerinin nasıl daha etkin bir şekilde kullanılabileceğini yoğun bir şekilde araştırmayı hedeflediğini" açıklamıştır.

Ayrıca bu konuda yapılan Birleşik Krallık'taki pilot çalışmalar ile bankacılık düzenlemelerinin bilgisayar tarafından okunabilecek formatta hazırlanması ve raporlamaların otomatik bir şekilde gerçekleştirilmesine yönelik ortak bir çalışma yürütmekte olduğu bilinmektedir. Bu sayede düzenlemelere uyumun hem bankalar hem de denetim ve gözetim otoriteleri tarafından daha etkin bir hâle getirmesi beklenmektedir. Bu sonuçlar ile Türkiye'de de dijitalleşmenin geldiği noktadan sonrası için; FinTech ekosisteminin yanına RegTech ve SupTech ekosistemlerinin çalışmalarına başlanmasının ve yapay zekâlı denetim ve gözetim sistemlerinin oluşturulmasının faydalı olacağı değerlendirilmektedir.

\section{REFERENCES}

Asadi, S., Nilashi, M., Husin, A. R., \& Yadegaridehkordi, E. $(2017,12)$. Customers perspectives on adoption of cloud computing in banking sector. Information Technology and Management, 18(4), 305-330.

Bátiz-Lazo, B. (2018). Cash and Dash: How ATMs and Computers Changed Banking. Oxford Univercity Press.

Buttar, R. (2019). Digitisation Becoming Crucial for Tackling Regulatory Fragmentation. Global Risk Regulator: https://www.globalriskregulator.com/Subjects/Reporting-and-Governance/Digitisation-becoming-crucial-for-tackling-regulatoryfragmentation adresinden alındı

Carbó-Valverde, S., Cuadros-Solas, P. J., \& Rodríguez-Fernández, F. (2020). The effect of banks' it investments on the digitalization of their customers. Global Policy, 11(1), 9-17.

Casolaro, L., \& Gobbi, G. (2007). Information technology and productivity changes in the banking industry. Economic Notes, 36, 43-76.

Crowley, M. J. (2019). Book Reviews - Cash and Dash. Essays in Economic \& Business History, 37, 252-254.

Davis, F. D., Bagozzi, R., \& Warshaw, P. R. (1989). User acceptance of computer technology: a comparison of two theoretical models. Management Science, 35(8), 982-1003.

Demirel, Ö. (1993). Eğitim Terimleri Sözlüğ̈̈. Ankara: Usem Yayınevi.

Feridun, M. (2020). Küresel Bankacılık Düzenlemelerinin Dünü, Bugünü ve Yarını. İstanbul: Türkiye Bankalar Birliği.

$\mathrm{He}$, Z. (2015). Rivalry, market structure and innovation: the case of mobile banking. Review of Industrial Organizations, 2(47), 219-242.

IMF. (2017). Fintech and Financial Services: Initial Considerations. IMF, Monetary and Capital Markets, Legal, and Strategy and Policy Review Departments. 122020 tarihinde https://www.imf.org/en/Publications/Staff-Discussion-Notes/Issues/2017/06/16/Fintech-and-FinancialServices-Initial-Considerations-44985.

Mishkin, F. S. (2007). Para,Bankacllık ve Finansal Piyasalar Iktisadı. Boston: 3D Yayınevi.

Organisation for Economic Co-operation and Development (OECD). (2017). Going Digital: Making the Transformation Work for Growth and Well-being', Meeting of the OECD Council at Ministerial Level. 2017. Paris: OECD.

Öztürk, Y. K., \& Akdağ, İ. (2017). Kapitalist sistemin kriz ve yükselişleri: uzun dalgalar teorisi. Turkish Studies, 12(24), 147-158.

Xue, M., Hitt, L. M., \& Chen, P.-Y. (2011, 02). Determinants and outcomes of internet banking adoption. Management Science, 2(57), 291307. 